\title{
Cost Benefit Analysis of Various California Renewable Portfolio Standard Targets: Is a 33\% RPS Optimal?
}

\author{
Omid M. Rouhani ${ }^{\mathrm{a},}{ }^{*}$, Debbie Niemeier ${ }^{\mathrm{b}}, \mathrm{H}$. Oliver Gao $^{\mathrm{c}}$, and Germà Bel ${ }^{\mathrm{d}}$ \\ (Forthcoming in Renewable \& Sustainable Energy Reviews)
}

\begin{abstract}
a, ${ }^{*}$ Corresponding author, Department of Civil Engineering and Applied Mechanics, McGill University, 817 Sherbrooke Street West, Montreal, Quebec, Canada; Email: omrouhani@ucdavis.edu

${ }^{\mathrm{b}}$ Department of Civil and Environmental Engineering, One Shields Avenue, University of California, Davis, California, United States.; Email: dniemeier@ucdavis.edu

${ }^{\mathrm{c}}$ School of Civil and Environmental Engineering, Cornell University, Hollister Hall, Ithaca, NY 14853, USA.; Email: hg55@,cornell.edu

${ }^{\mathrm{d}}$ Departament de Politica Econòmica, Universitat de Barcelona, Avd. Diagonal 690, 08034 Barcelona, Spain; Email: gbel@ub.edu
\end{abstract}

\begin{abstract}
Renewable Portfolio Standards (RPSs') require that a certain fraction of the electricity generated for a given region be produced from renewable resources. California's RPS mandates that by $2020,33 \%$ of the electricity sold in the state must be generated from renewables. Such mandates have important implications for the electricity sector as well as for the whole society. In this paper, we estimate the costs and benefits of varying 2020 California RPS targets on electricity prices, greenhouse gas (GHG) emissions, criteria pollutant emissions, the electricity generation mix, the labor market, renewable investment decisions, and social welfare. We have extended the RPS Calculator model, developed by Energy and Environmental Economics (E3) Inc., to account for distributions of fuel and generation costs, to incorporate demand functions, and to estimate the effects of RPS targets on GHG emissions, criteria pollutant emissions, and employment. The results of our modeling provide the following policy insights: (1) the average 2020 electricity price increases as the RPS target rises, with values ranging between $\$ 0.152$ and $\$ 0.175 / \mathrm{kWh}$ (2008 dollars) for the 20\% RPS to 50\% RPS, respectively; (2) the 33\% and 50\% RPS targets decrease the GHG emissions by about 17.6 and 35.8 million metric tons of carbon dioxide equivalent $\left(\mathrm{MMTCO}_{2} \mathrm{e}\right)$ relative to the $20 \%$ RPS; (3) the GHG emission reduction costs of the RPS options are high ( $\$ 71$ to $\$ 94$ per ton) relative to results from policy options other than RPS or prices that are common in the carbon markets; and (4) a lower target (e.g., a 27\% RPS) provides higher social welfare than the 33\% RPS (mandate) under low and moderate $\mathrm{CO}_{2}$ social costs (lower than $\$ 35 /$ ton); while a higher RPS target (e.g., $50 \%$ ) is more beneficial when using high $\mathrm{CO}_{2}$ social costs or with rapid renewable technology diffusion. However, under all studied scenarios, the mandated 33\% RPS for California would not provide the best cost/benefit values among the possible targets and would not maximize the net social benefit objective.
\end{abstract}

KEYWORDS- renewable portfolio standard, benefit/cost analysis, social welfare, GHG emissions, electricity generation, sustainable energy. 


\section{Contents}

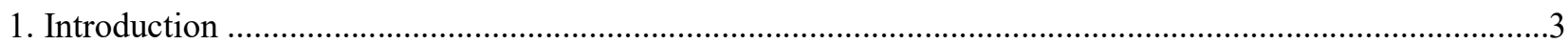

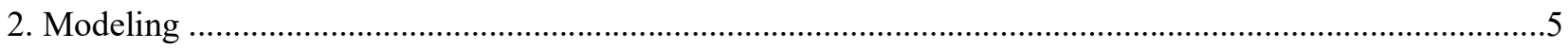

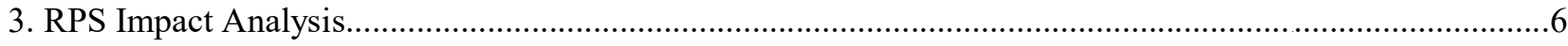

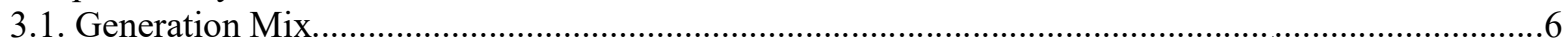

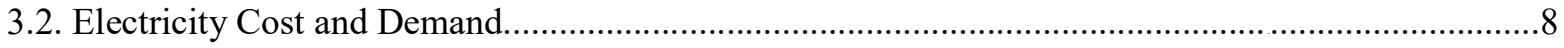

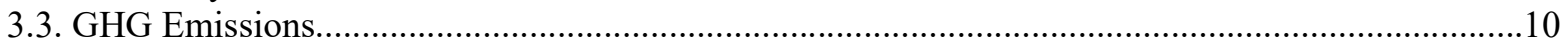

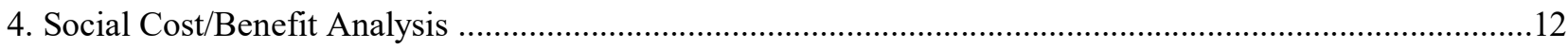

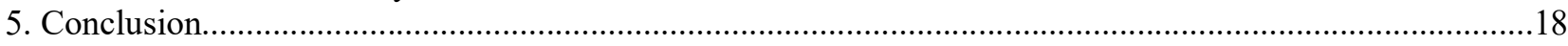

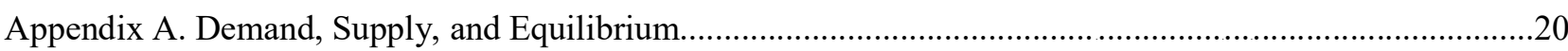

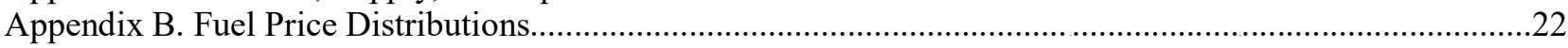

Appendix C. GHGs, Criteria Pollutants, and Employment Calculations.....................................................23

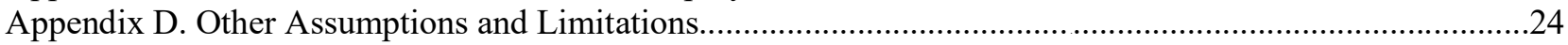

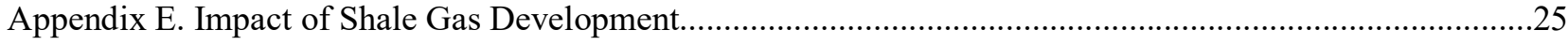

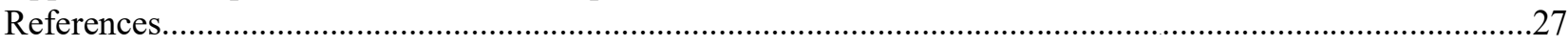




\section{Introduction}

Renewable electricity resources are critically important in the efforts to address climate change [1] and to provide a clean source of domestic energy [2] that could also increase employment opportunities [3]. The renewable portfolio standard (RPS) has been adopted worldwide to encourage the use of renewables. Twenty nine out of 50 U.S. states plus the District of Columbia have adopted mandatory RPS standards [4]. For the state of California, Senate Bill SB2 (X1) mandates that 33\% of the electricity sales by all electricity retailers be generated from renewable resources (without constraining the types of renewables to be used) by 2020 [5], following an earlier RPS target of $20 \%$ for 2010 . California's RPS target is one of the most aggressive in the U.S. The implications of RPS targets are far-reaching however, and policy makers should carefully examine the range of potential effects when designing such aggressive RPS targets.

RPS policies can significantly influence various indicators of the electricity sector [7-10]. As one important indicator, higher costs for electricity production have shown to be a usual byproduct of RPS programs (e.g., see Crane et al. [9], Barbose et al. [10], and Kydes [11]). Two California specific analyses have predicted that the mandated target of $33 \%$ is an ambitious RPS target requiring major new transmission lines [8], and that the costs of statewide electricity generation would increase between about 2\% [12] and 7\% [8] relative to a 20\% RPS. RPS policies can also affect investment in renewables as well as adoption of renewable technology. With respect to investment, some evidence indicates that lack of a requirement for new capacity, coupled with an ability to deploy out-of-state renewable generation, could even reduce investment in renewable generation under RPS programs [13-14].

Despite the relatively successful implementation of numerous RPS programs worldwide, it is unclear (especially by looking at their estimated impacts on the electricity sectors) whether the basic reasoning behind RPS adoption is driven by factors such as the environment and promotion of domestic energy sources or rather (in few cases) by political/administrative considerations and powerful private lobbies [15-16]. Finally, the choice of the RPS target levels has been questioned in certain states, such as California [17].

To address these concerns, one key aspect of RPS targets that has not been well studied is how varying target levels can impact society as a whole. In one of the very few studies analyzing the welfare effects for the U.S., Palmer and Burtraw [18] compared different RPS targets along with a cap-and-trade and a renewable energy production tax credit policy and found that to achieve a comparable reduction in GHGs, the cap-and-trade is the most cost effective option with $\$ 82$ per ton of $\mathrm{CO}_{2}$, while the $15 \%$ RPS costs $\$ 148$ per ton (well beyond the present market values) and the $20 \%$ RPS costs $\$ 532 /$ ton. However, 
the estimated cost of $\mathrm{CO}_{2}$ abatement from RPS programs is much higher than the cost range (\$11 to \$34 per ton of $\mathrm{CO}_{2}$ ) found by Johnson [19]. The Palmer and Burtraw study [18] can also be contrasted with that of Nogee et al. [20] where the results suggest that not only do RPS targets reduce electricity prices, but a 20\% RPS offers higher benefits for society than a 10\% RPS.

Nearly all of the RPS studies to date [18 \& 21-22] lack detailed cost benefit analyses on how, and under what conditions, an RPS target should be implemented. For example, although Palmer and Burtraw [18] were very detailed in their cost analyses, the study falls short in considering the overall effects of an RPS policy on employment, generation mix, change in demand, etc. In addition, most of the previous social welfare studies, including Palmer and Burtraw [18] and Bird et al. [22], assume the same RPS target for all states in the US, which is simply impossible to implement. A similar concern was echoed by Mosey and Vimmerstedt [23]. The study called for advancement in state-of-the-art methodologies for assessing RPS policies. Our review of these past efforts demonstrate that critical elements of the welfare changes resulting from an RPS have not been exhaustively catalogued or examined in detail.

In this research, we develop a new and comprehensive framework that integrates cost benefit analysis into an examination of RPS targets by region. Our study contributes to the state of knowledge in two ways. First, as shown earlier, the inclusion of social welfare into an examination of RPS targets is a critically important, but as yet remains rather unexplored dimension of analysis. Second, this study develops a regional research framework that examines the welfare aspects to RPS target setting at a local level. A regional analysis could closely align with local utility provision boundaries and the availability of local renewable resources.

In this study, we analyze the effects of implementing various RPS targets in California on regional electricity prices, consumers, generation mix, GHG emissions, criteria pollutant emissions, renewable resource portfolios, employment in the electricity sector, and the effects on electricity demand and supply under different fuel price settings and environmental conditions. We employ the RPS Calculator model, developed by Energy and Environmental Economics (E3) Inc., and extend its analytical engine by improving its forecast accuracy and expanding its impact analysis.

Our methodology is more comprehensive than those employed in most previous RPS studies, especially in terms of (1) the use of stochastic inputs, (2) the detailed calculations of criteria pollutant and GHG emissions and employment, and (3) the embedded modeling feature of responsive demand to prices. While results from our study on California's RPS cannot be extensively generalized to other states because of difference in factors such as RPS requirements and potentials/limits across states, our new welfare assessment framework can be applied in almost any context to analyze RPS targets in other 
states as well as to evaluate California's future RPS targets (e.g., the 2030 target which is the topic of current debates in the state).

\section{Modeling}

When designing RPS targets to regulate the electricity sector, three key questions must be considered:

(1) How will the state meet the target (i.e., how much change will be needed in the generation portfolio),

(2) what will be the costs of reaching the target, and (3) what are the broader welfare effects of implementing the targets? To provide detailed answers to these questions, we need a comprehensive modeling framework. To that end, we employed the RPS Calculator as our benchmark model. The RPS Calculator estimates the renewable resources that must be procured to meet California's RPS goals, using very detailed information on the commercial renewable projects and the transmission and generation costs of producing electricity from renewables [24].

The RPS Calculator was developed by Energy and Environmental Economics (E3) Inc. for the purpose of evaluating different RPS targets for California [24]. Using fixed demand estimations, the model constructs the supply function (See Appendix A for more details) with the use of detailed information on the commercial projects, i.e., projects that are expected to come online in the near (or mid) term, and the transmission and generation costs of producing electricity from renewables. The calculations start with an estimation of the renewable resources statewide that the utilities in California must procure between 2012 and 2020 to meet a specified RPS target by 2020. Then, the RPS Calculator ranks and selects the renewable resources needed to meet the RPS target(s) based on their cost effectiveness until the new renewables equal the required RPS target renewable sales.

We have extended the RPS Calculator model in several ways. First, electricity demand in the original RPS Calculator is fixed, using the California Energy Commission (CEC) study demand forecasts [25]. However, the CEC study have estimated demand by using electricity generation costs that are based on the 20\% RPS (the initial target); as a result, the demand estimates are inconsistent with the demand expected from implementing other RPS targets because the corresponding electricity costs (prices) would be different for each target. To address this issue, we incorporate short-run and long-run demand functions that are responsive to prices and estimates the electricity demand endogenously. Based on the average estimates found from various studies [26-28], we assume a short-run elasticity of 0.1 and a long-run elasticity of -0.50 . With this modification to the RPS Calculator, electricity demand responds to changes in the electricity sector that affect electricity prices (See Appendix A for additional details about how demand will be determined/updated). Second, instead of using point estimates of input parameters (while it is much more likely that the estimated value will take on a range of values), our 
modified model allows the use of random parameters based on various types of distributions. In fact, considering uncertainty associated with future fuel prices, we allow fuel prices to be random variables with normal distributions. By randomizing these key parameters/input, our modified RPS model is able to capture the effects of different fuel price combinations (See Figure B1, Appendix B).

In addition, we have added three new modules to the RPS Calculator, calculating (1) the changes in GHG emissions, (2) changes in criteria pollutant emissions, and (3) changes in employment, under different RPS targets. We estimate GHG emissions based on two sets of emission rates (See Table C1row a, Appendix C): (1) the non-life-cycle analysis (non-LCA) values inherited from the RPS Calculator; and (2) the LCA values. The health-related benefits of reductions in criteria pollutant emissions (which accounts for mortality damages of $\mathrm{SO}_{2}, \mathrm{NO}_{\mathrm{x}}$, and primary $\mathrm{PM}_{2.5}$ emissions) are calculated based on the assumptions discussed in Appendix C (Table C1- row b). Changes in employment (from the 20\% RPS target) are estimated based on changes in the generation mix, applying job creation rates (the average number of job-years per GWh for each type of generation) on the electricity generation mix (Table C1- row c, Appendix C). Finally, Appendix E explains our assumptions related to generation cost minimization and California's carbon market and lists key limitations of our model.

As discussed above, our methodology is far more comprehensive than those employed in most previous RPS studies, especially since it provides detailed information required to conduct a comprehensive social benefit/cost analysis. Appendices A through D provide details for all of the inputs considered in our modeling, the modifications made to the RPS Calculator, the procedures used to estimate various outputs, and the limitations of our methods.

\section{RPS Impact Analysis}

\subsection{Generation Mix}

One of the major goals for implementing RPS targets is to promote the kinds of technology transformations needed to lower the long-run costs of producing electricity and to encourage resource diversity [8]. In fact, most beneficial outcomes of an RPS target are derived from changes in generation mix, especially from changes in renewable generation. In addition, the generation mix and technology costs subsequently affect electricity pricing and demand.

Note that in our model, we assume that: (1) changes in conventional generation are based mainly on levels of natural gas generation; (2) the limits on the percentage of electricity supplied by out-of-state generation (as a separate category) are applied to each of the three compliance periods, in accordance 
with the SB2 (1X) [5]; and (3) the relative magnitude of conventional generation and renewable generation is mostly determined by the RPS target. Based on these assumptions, our model estimates that total 2020 in-state and out-of-state renewable generation would increase from 45,000 and 17,000 GWhs (for the 20\% RPS target) to 117,000 and 23,000 GWhs (for the 50\% RPS target). The estimated ratio of in-state to out-of-state renewable generation varies by the RPS target, ranging from 2.5 to 1 (RPS 20\%) to 5 to 1 (RPS 50\%) by 2020. With these in mind, Figure 1 shows the 2020 in-state (2-a) and out-of-state (2-b) generation mix of renewable resources for each RPS target. Figure 1 also shows the 2013 in-state and out-of-state renewable portfolio (the current renewable mix) for comparison. Note that the 2013 portfolio is similar to the 2020 portfolios for the $20 \%$ and $27 \%$ RPS targets (since in 2013 , around $20 \%$ of in-state generation was from renewables). However, because of the differences in demand and costs in different years, the 2013 and 2020 portfolios should be compared with caution.

For 2020 out-of-state generation, wind would be the main renewable resource (67\% to $75 \%$ ) under almost all RPS targets. For in-state generation, geothermal (37\%) and wind (27\%) are the primary resources for the 20\% RPS target, while solar (34\%) and wind (30\%) are the dominant resources for the $50 \%$ RPS target. The major portfolio change from the 20\% RPS to the 50\% RPS occurs with a sharp increase in solar PV generation followed by increases in wind and solar thermal generation. As reflected in Figure 1, California will be able to use a wide variety of resources, including biogas, biomass, geothermal, small hydro, solar PV, solar thermal, and wind to meet its RPS targets.
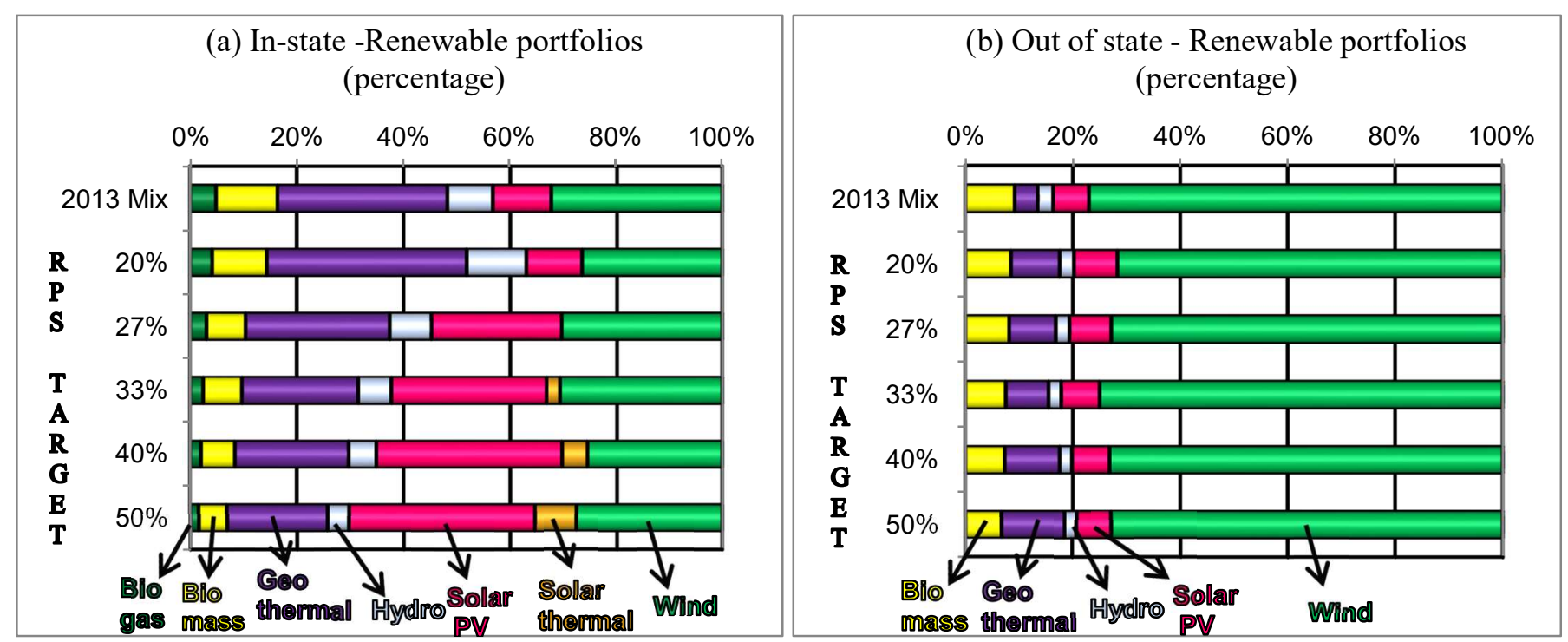

Fig. 1. 2013 renewable mix and 2020 renewable portfolios of various RPS targets for (a) in-state; and (b) out-ofstate generation. 


\subsection{Electricity Cost and Demand}

Each RPS target induces a change in the electricity generation mix, which affects the electricity generation costs (e.g., higher costs are typically associated with using generally more expensive renewables that would not be cost effective to use without an RPS). The change in generation mix also distorts electricity prices, which, in turn, influences electricity demand. Figure 2 shows the resulting average costs of electricity generation to meet various RPS targets in 2015 and 2020. Electricity prices are reported in terms of 2008 cents/kWh. We calculate these prices by dividing the total electricity generation costs by total retail sales with no consideration for the price variation across different electric utilities. To account for and simulate the effects of different combinations of fuel costs (Figure B1, Appendix B), the model was run one hundred times for each RPS target. Since the fuel prices are random variables, the outputs are also random variables with expected values (averages), and maximum and minimum values.

As expected, Figure 2 shows that the average 2020 electricity prices would increase as the RPS target rises, with the average 2020 price for the 50\% RPS as the highest. Average electricity prices range from $\$ 0.152 / \mathrm{kWh}$ for the $20 \%$ RPS to $\$ 0.175 / \mathrm{kWh}$ for the $50 \%$ RPS. These results show that a $50 \%$ RPS would increase price by $15 \%$ compared to the average price associated with a $20 \%$ RPS.

Relative to the CPUC [8] 2020 reference price estimate of $\$ 0.169 / \mathrm{kWh}$ for the $33 \%$ RPS, our average estimate of $\$ 0.162 / \mathrm{kWh}$ is lower by about $4 \%$, mainly because we allow demand to decrease as a result of higher electricity prices derived from meeting higher RPS targets. Over time, however, lowered demand for electricity induces lower prices. For high RPS targets, we argue that demand response can mitigate electricity prices to some extent. As a result, the electricity market would not face substantially higher prices when implementing high RPS targets. However, this result cannot be generalized to other states since California has the potential to promote different types of renewables at lower costs, compared to many other states in the U.S. Another major reason for our lower price estimate is that the more up-to-date natural gas price forecasts are substantially lower than those assumed in the CPUC study, as a result of rapid shale gas developments in recent years. As discussed in Appendix E (See Table E1), the impact of the change in natural gas prices on the analysis is substantial. In fact, the sudden decline in natural gas prices has made renewables and RPS policies less favorable to the society (or reduced social welfare benefits of RPS programs) since it widens the gap between the cost of renewable electricity generation and the (substantially-reduced) cost of conventional natural gas generation. Therefore, the initial estimates (with much higher natural gas prices) about the RPS impacts that led to the choice of the mandated 33\% RPS are not valid. 
As shown in Figure 2, our model predicts that the increase in electricity prices would not be linear with respect to RPS targets. This is because the commercial renewable projects come online in different years and technology diffusion influences the prices in a complex manner.

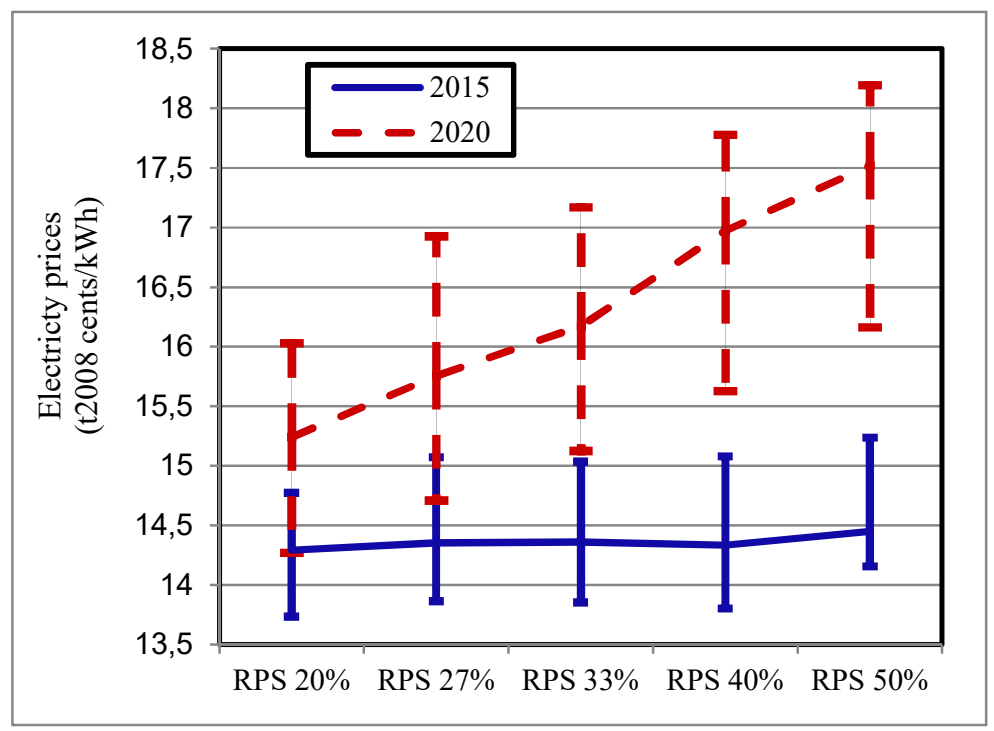

Fig. 2. 2015 and 2020 annual electricity prices from implementing various RPS targets.

Figure 2 indicates that a 2020 RPS target of $27 \%$ would increase the 2020 average price, relative to the respective $20 \%$ RPS price, by about $3 \%$. In contrast, the mandated $33 \%$ RPS would increase the price by $6 \%$. Figure 2 also shows the estimated range and the standard errors of the 2015 and 2020 prices in addition to the average prices. For the maximum electricity prices (resulting from high conventional fuel price conditions), renewables become less costly than conventional generation. This makes renewables an attractive option irrespective of the RPS target level. The electricity prices resulting from the RPS target levels differ significantly only for the cases in which conventional fuel prices are medium or low. Specifically, these targets could be met with no price increase when natural gas prices are high. However, high natural gas prices are very unlikely with the increasing production of shale gas [29].

Figure 3 shows the average annual demand in thousand GWhs for different RPS targets, along with the minimum and maximum demand obtained from different simulation runs. The short-run demand (2015) and the long-run demand (2020) have been computed and reported based on the 
corresponding prices. Relative to the 20\% RPS demand in 2020, an average decrease in demand ranging from $1 \%(27 \%$ RPS) to $6 \%(50 \%$ RPS $)$ is projected by 2020 . These reductions in demand will lead to social welfare losses (discussed later); that is, consumers are expected to be worse off when they should be consuming less electricity.

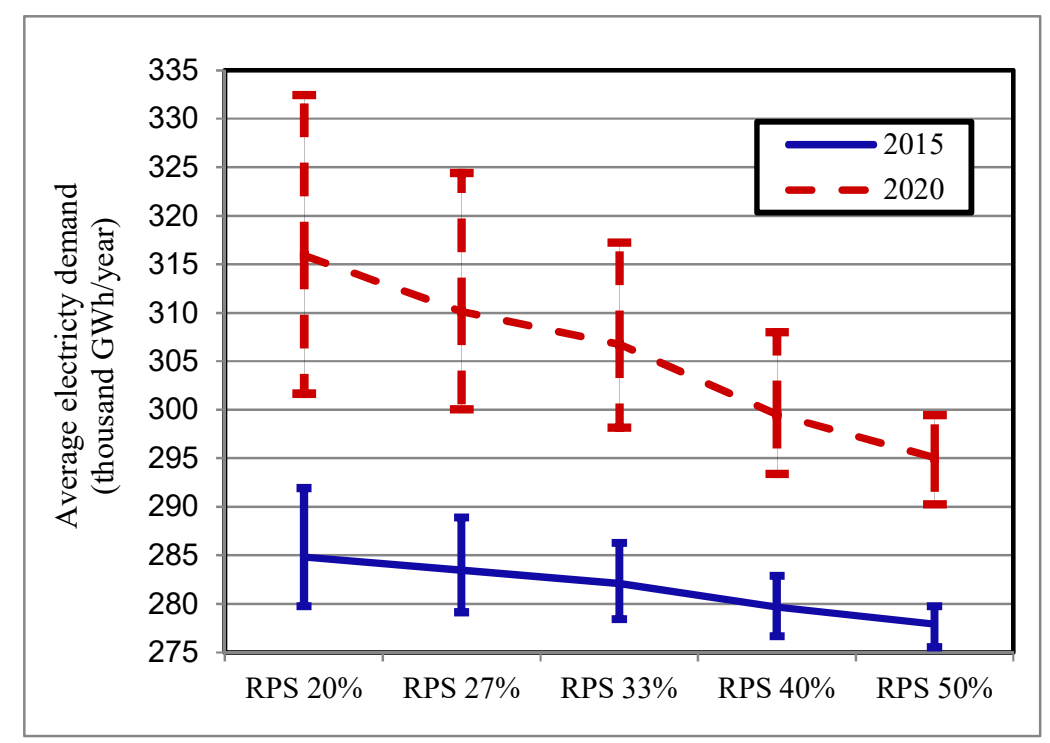

Fig. 3. 2015 and 2020 annual electricity demand for various RPS targets.

\subsection{GHG Emissions}

RPS targets are designed to proactively boost a clean energy policy. In fact, one of the main performance measures when evaluating the effectiveness of an RPS is the resulting GHG emissions reduction. Based on the life cycle analysis (LCA) values in Table C1 (Appendix C), Figure 4 shows the resulting average $\mathrm{CO}_{2}$ equivalent GHG emission reductions from various RPS targets relative to the $20 \%$ RPS. As we will observe in the final welfare calculations, the GHG reductions using the LCA values are similar to the reductions using non-LCA values since we are looking at the GHG reductions in a comparative sense.

Because of responsive demand to prices, when the price of electricity increases with higher RPS targets due to the adoption of more costly renewables, the demand for electricity decreases. Therefore, the reductions in GHG emissions from a higher RPS target stem from two factors: (1) a higher proportion of renewables in the portfolio that replace conventional resources; and (2) electricity demand reduction in response to higher prices.

As can be observed in Figure 4, the 33\% and 50\% RPS targets decrease the GHG emissions by about 17.6 and 35.8 million metric tons of carbon dioxide equivalent $\left(\mathrm{MMTCO}_{2} \mathrm{e}\right)$ relative to the $20 \%$ 
RPS. The 17.6 $\mathrm{MMTCO}_{2} \mathrm{e}$ decrease is comparable to the California Air Resources Board's estimation [30] that a 33\% RPS could reduce GHG emissions by $14.2 \mathrm{MMTCO}_{2} \mathrm{e}$. Our estimate is slightly higher, mainly because we have included a demand response mechanism.

For lower RPS targets, the majority of the reductions will be achieved by 2015-2016; then, as the fuel generation mix and demand change in later years, GHG reductions will remain nearly constant. For higher RPS targets, however, GHGs will decrease steeply in 2018 and 2019 as we approach the 2020 deadline. The $33 \%$ and $27 \%$ RPS can be achieved with a smooth transition in generation early on, while the higher RPS targets will result in generation changes and GHG reductions closer to 2020. This result has important implications for policy design since the present GHG reductions could be much more valuable than the future GHG reductions to control climate change. In fact, a low RPS target is not substantially different from a high RPS target in providing the actions needed to immediately reduce $\mathrm{CO}_{2}$ emissions.

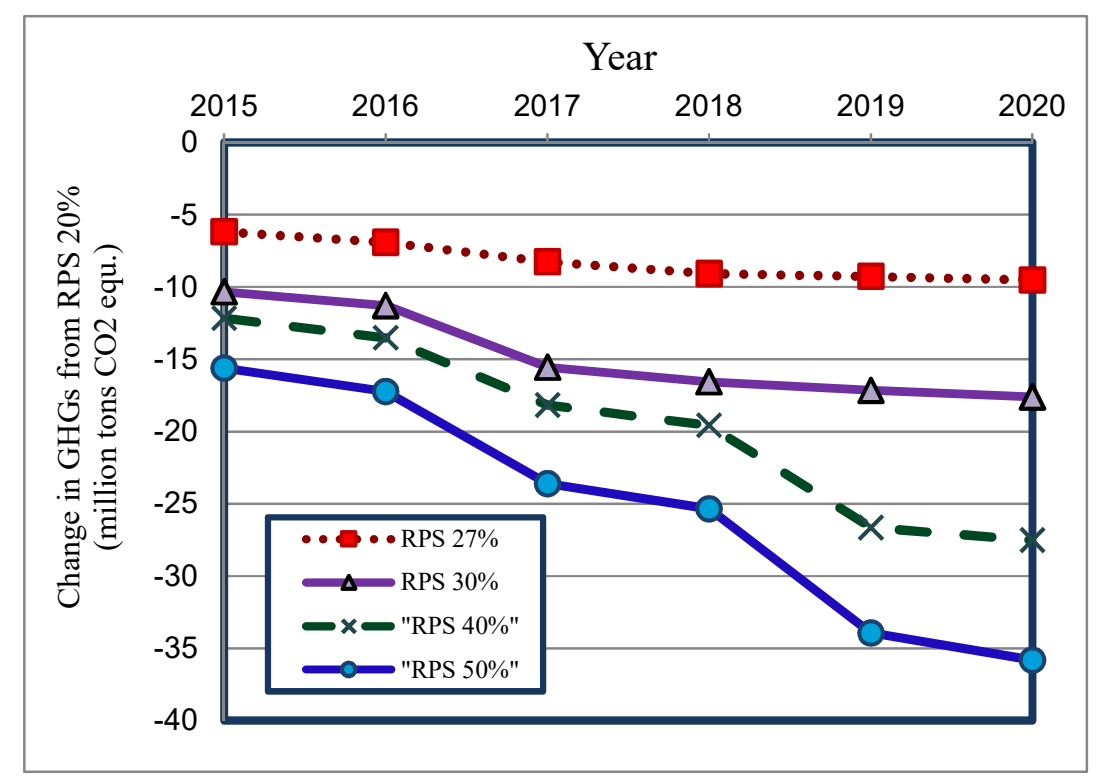

Fig. 4. Average LCA GHG emissions reduction from implementing various RPS targets, relative to the $20 \%$ RPS.

The values shown in Figure 4 report the total GHG reductions only. From a climate change policy perspective, an equally useful measure is the cost-effectiveness of reducing GHG emissions in terms of dollars spent per one unit reduction. Figure 5 shows the 2020 average cost per ton of GHG emission reduction for various RPS targets (without considering co-benefits), using the 20\% RPS target level as the baseline. Not surprisingly, the costs per ton increase as the RPS target increases. Figure 5 also shows that the $27 \%$ RPS target could reduce GHG emissions, relative to the $20 \%$ RPS, by a 
substantial unit reduction cost, with a slight increase in the cost for higher RPS targets (i.e., from an average cost of $\$ 71$ per ton GHG reduction under the 27\% RPS to $\$ 94$ per ton GHG emission reduction for the 50\% RPS). Interestingly, these estimated GHG emission reduction costs are relatively higher when compared to those reported in the literature [31-32], or compared to the prices prevalent in the carbon markets [33] and the newly established California market carbon prices [34].

This higher cost verifies the results found in other studies that other policy options could be more cost effective than RPS; for example, the carbon markets induce lower $\mathrm{CO}_{2}$ prices/costs than the RPS targets $[18,22]$. Note that our estimates are generally lower than the costs of abatement from RPSs found in the Palmer and Burtraw study [18] and are moderately higher than the Johnson study [19]'s estimates. However, these comparisons should be done with care since these estimates are found for different case studies and for different RPS targets.

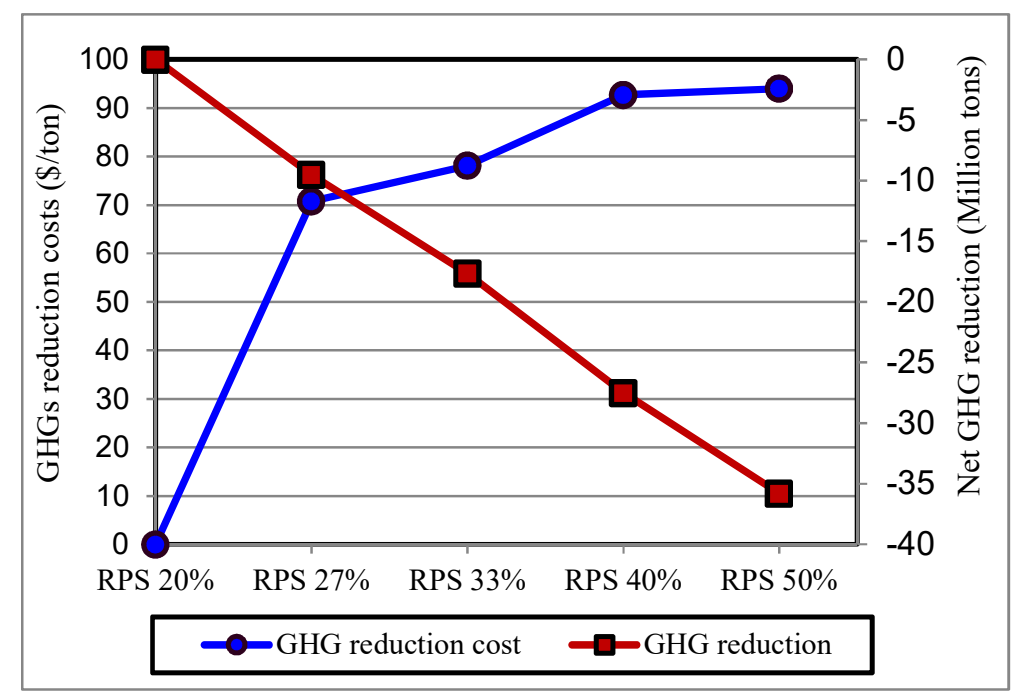

Fig. 5. 2020 average GHG emission reduction costs $\left(\$ / M_{M T C O} e\right)$ and the corresponding 2020 average GHG reductions $\left(\mathrm{MMTCO}_{2} \mathrm{e}\right)$ for each RPS target.

\section{Social Cost/Benefit Analysis}

The broader impact of RPS policies should also be included in an RPS policy analysis. In this regard, a detailed social cost/benefit analysis provides us with invaluable insights about how to design these policies. To this end, major stakeholders' gains and losses from implementing each RPS target should be compared to a base target (the $20 \%$ RPS). In general, the total social welfare change is the sum of the change in consumer surplus, the change in producer surplus, the change in government surplus, and the 
change in employee surplus [35]. The corresponding welfare values in our analysis are from (1) higher costs of generation for producers, (2) electricity demand reductions, (3) emissions mitigations, (4) higher subsidies and lower taxes for government, and (5) employment gains. We ignore government loss since the subsidies for renewables will be gradually removed over time, and since electricity generation costs include the subsidies to some extent.

To estimate the social benefit/cost effects of different RPS targets, we need to make a few assumptions about relevant parameters/coefficients, including the emissions rate generated from each renewable technology, the social cost of GHG emissions, the marginal health-related benefit of reducing criteria pollutant emissions, the social value of each unit of employment, and the cost trend of renewable generation.

By creating various scenarios with combinations of different parameter values, we can develop a number of useful policy insights. Table 1 describes the main features assumed for the base case (Scenario 1) along with seven alternative scenarios. Scenario 1 is based on the life cycle analysis (LCA) GHG emission rates, $\mathrm{CO}_{2}$ social cost of $\$ 30$ per ton, the social value of $\$ 50,000$ per job-year created, the base carbon market price forecasts [36], and the projected costs for renewable electricity generation. According to estimates from Bureau of Labor Statistics [37], the annual employment value of $\$ 50,000$ per job is based on the 2013 average wage of solar and wind installers and technicians in California. All other scenarios are designed by examining the effects of changes in features of Scenario 1, as Scenario 1 represents our anticipated values of social costs of carbon, carbon market prices, renewable technology diffusion trends, etc.

Table 1 Main features of base scenario and alternative scenarios.

\begin{tabular}{lllcccc}
\hline & Definition & $\begin{array}{l}\text { Emission } \\
\text { rates }\end{array}$ & $\begin{array}{l}\mathrm{CO}_{2} \text { cost } \\
(\$ / \text { ton })\end{array}$ & $\begin{array}{l}\text { Value of labor } \\
(\$ / \text { year })\end{array}$ & $\begin{array}{l}\text { Renewable } \\
\text { cost trend }\end{array}$ & $\begin{array}{l}\text { Carbon } \\
\text { market }\end{array}$ \\
\hline Scenario 1 & Base & LCA & 30 & 50,000 & Base & base estimate \\
Scenario 2 & Non-LCA & Non-LCA & 30 & 50,000 & Base & base estimate \\
Scenario 3 & High $\mathrm{CO}_{2}$ price & LCA & 60 & 50,000 & Base & base estimate \\
Scenario 4 & Very high $\mathrm{CO}_{2}$ price & LCA & 90 & 50,000 & Base & base estimate \\
Scenario 5 & Low labor value & LCA & 30 & 25,000 & Base & base estimate \\
Scenario 6 & No labor benefit & LCA & 30 & 0 & Base & base estimate \\
Scenario 7 & Technology advancement & LCA & 30 & 50,000 & Major drop & base estimate \\
Scenario 8 & Low carbon market prices & LCA & 30 & 50,000 & Base & CARB Floor \\
\hline
\end{tabular}


Table 2 and Table 3 report the primary 2018 and 2020 social-welfare-related outputs from various RPS targets for Scenario 1 (the base case). The social benefits/costs of using any RPS target relative to the $20 \%$ RPS is categorized into five dimensions: (1) welfare losses from reducing electricity demand based on the rule of half (also called the rule of one-half), which approximates the changes in consumer surplus for small changes in supply (here electricity prices). With the assumption of fixed and linear demand curves, the welfare decrease as a result of losing past customers is calculated by multiplying half of the additional costs to consumers by the decrease in the consumption level [38-39]; (2) welfare losses from inducing higher electricity generation costs; (3) welfare gains from decreasing GHG emissions; (4) welfare gains from reducing criteria pollutant emissions; and finally (5) welfare gains from increasing employment. We assumed that the summation of these elements represents the total welfare change resulting from implementing each RPS target. Note that the generation costs in Tables 2 and 3 include transmission costs and integration costs along with production costs.

For the base scenario (Scenario 1), in both 2018 and 2020, the main drivers of welfare change among different cases are changes in generation cost and employment, followed by GHG reductions and electricity demand decrease. Electricity demand reductions are expected to have a relatively minor effect on welfare since the electricity prices and demand levels do not increase drastically relative to the $20 \%$ RPS.

As shown in Table 2, all RPS targets in 2018 would reduce total welfare relative to the $20 \%$ RPS target by $\$ 102.8$ million (the $27 \%$ RPS) to $\$ 494.9$ million (the 50\% RPS). As expected, total social welfare from RPS targets would increase over time (from 2018 to 2020) since renewable electricity generation will become less expensive; as result, the relatively lower increase in generation costs could be completely offset by the benefits of lower emissions and higher employment. Social welfare gains of RPS targets are expected to increase further after 2020. Welfare benefit/cost calculations beyond 2020 require assumptions that are out of the context of this study.

For 2020 (Table 3), an RPS target of 27\% would increase total social welfare by $\$ 33.2$ million over that of the $20 \%$ RPS. The main drivers of for higher social welfare comprise higher employment (which would increase welfare by $\$ 378.1$ million), the reduction in GHG emissions (which would increase welfare by $\$ 285$ million), and the reduction in criteria pollutant emissions (which would increase welfare by $\$ 57.2$ million), but these are counterbalanced by the higher generation costs which would decrease social welfare by $\$ 672.3$ million, and the welfare decrease resulting from reducing electricity demand which would be negligible (\$-14.8 million). All other RPS targets would result in 
losses of total welfare relative to the $20 \%$ RPS, and the loss would increase with the RPS target, resulting, for example, in a $\$ 478.3$ million decrease in social welfare for the $50 \%$ RPS. 
Table 22018 social benefit/cost analysis for various RPS targets under Scenario 1.

\begin{tabular}{|c|c|c|c|c|c|c|c|c|c|c|c|}
\hline & \multicolumn{3}{|c|}{ Electricity demand } & \multicolumn{2}{|c|}{ Electricity cost } & \multicolumn{2}{|c|}{ GHGs } & \multirow{2}{*}{\begin{tabular}{l}
\multicolumn{1}{c}{$\begin{array}{c}\text { Criteria } \\
\text { pollutant }\end{array}$} \\
(4) Change in \\
Welfare \\
(\$ Million)
\end{tabular}} & \multicolumn{2}{|c|}{ Employment } & \multirow{2}{*}{$\begin{array}{c}\text { Total Change } \\
\text { in Welfare } \\
\text { (\$ Million) }\end{array}$} \\
\hline & $\begin{array}{l}\text { Total } \\
\text { Electricity } \\
\text { Demand } \\
(\mathrm{GWh})\end{array}$ & $\begin{array}{l}\text { Ave. } \\
\text { Price } \\
(\$ / k W h)\end{array}$ & $\begin{array}{l}\text { (1) Change } \\
\text { in Welfare } \\
\text { (\$ Million) }\end{array}$ & $\begin{array}{l}\text { Total Costs- } \\
\text { (\$ Million) }\end{array}$ & $\begin{array}{l}\text { (2) Change } \\
\text { in Welfare } \\
\text { (\$ Million) }\end{array}$ & $\begin{array}{l}\text { Total GHG } \\
\text { reductions (ton } \\
\mathrm{CO}_{2} \text { equ.) }\end{array}$ & $\begin{array}{l}\text { (3) Change } \\
\text { in Welfare } \\
\text { (\$ Million) }\end{array}$ & & $\begin{array}{l}\text { Jobs/year } \\
\text { change }\end{array}$ & $\begin{array}{l}\text { (5) Change } \\
\text { in Welfare } \\
\text { (\$ Million) }\end{array}$ & \\
\hline RPS $20 \%$ & 306,228 & 0.1483 & 0.0 & 41,368 & 0.0 & 0 & 0.0 & 0.0 & 0 & 0.0 & 0.0 \\
\hline RPS $27 \%$ & 301,869 & 0.1531 & -10.5 & 42,138 & -770.1 & $-8,937,507$ & 268.1 & 53.9 & 7,114 & 355.7 & -102.8 \\
\hline RPS $33 \%$ & 299,284 & 0.1568 & -29.5 & 42,783 & $-1,414.7$ & $-16,347,196$ & 490.4 & 98.9 & 14,395 & 719.8 & -135.1 \\
\hline RPS $40 \%$ & 293,893 & 0.1601 & -72.7 & 43,256 & $-1,887.2$ & $-19,318,820$ & 579.6 & 115.9 & 17,617 & 880.8 & -383.6 \\
\hline RPS $50 \%$ & 290,546 & 0.1641 & -123.4 & 43,922 & $-2,553.8$ & $-25,008,824$ & 750.3 & 149.4 & 25,653 & $1,282.7$ & -494.9 \\
\hline
\end{tabular}

Table 32020 social benefit/cost analysis for various RPS targets under Scenario 1.

\begin{tabular}{|c|c|c|c|c|c|c|c|c|c|c|c|}
\hline & \multicolumn{3}{|c|}{ Electricity demand } & \multicolumn{2}{|c|}{ Electricity cost } & \multicolumn{2}{|c|}{ GHGs } & \multirow{2}{*}{\begin{tabular}{l}
\multicolumn{1}{c}{$\begin{array}{c}\text { Criteria } \\
\text { pollutant }\end{array}$} \\
(4) Change in \\
Welfare \\
(\$ Million)
\end{tabular}} & \multicolumn{2}{|c|}{ Employment } & \multirow{2}{*}{$\begin{array}{l}\text { Total Change } \\
\text { in Welfare } \\
\text { (\$ Million) }\end{array}$} \\
\hline & $\begin{array}{l}\text { Total } \\
\text { Electricity } \\
\text { Demand } \\
(G W h) \\
\end{array}$ & $\begin{array}{l}\text { Ave. } \\
\text { Price } \\
(\$ / k W h)\end{array}$ & $\begin{array}{l}\text { (1) Change } \\
\text { in Welfare } \\
\text { (\$ Million) }\end{array}$ & $\begin{array}{l}\text { Total Costs- } \\
\text { (\$ Million) }\end{array}$ & $\begin{array}{l}\text { (2) Change } \\
\text { in Welfare } \\
\text { (\$ Million) }\end{array}$ & $\begin{array}{l}\text { Total GHG } \\
\text { reductions (ton } \\
\mathrm{CO}_{2} \text { equ.) }\end{array}$ & $\begin{array}{l}\text { (3) Change } \\
\text { in Welfare } \\
\text { (\$ Million) }\end{array}$ & & $\begin{array}{l}\text { Jobs/year } \\
\text { change }\end{array}$ & $\begin{array}{l}\text { (5) Change } \\
\text { in Welfare } \\
\text { (\$ Million) }\end{array}$ & \\
\hline RPS $20 \%$ & 315,922 & 0.1524 & 0.0 & 42,353 & 0.0 & 0 & 0.0 & 0.0 & 0 & 0.0 & 0.0 \\
\hline RPS $27 \%$ & 310,156 & 0.1576 & -14.8 & 43,025 & -672.3 & $-9,500,706$ & 285.0 & 57.2 & 7,562 & 378.1 & 33.2 \\
\hline RPS 33\% & 306,762 & 0.1617 & -42.7 & 43,731 & $-1,378.2$ & $-17,635,475$ & 529.1 & 106.2 & 15,530 & 776.5 & -9.1 \\
\hline RPS $40 \%$ & 299,548 & 0.1698 & -141.9 & 44,903 & $-2,550.1$ & $-27,505,656$ & 825.2 & 165.9 & 25,082 & $1,254.1$ & -446.8 \\
\hline RPS $50 \%$ & 295,078 & 0.1752 & -237.5 & 45,720 & $-3,367.2$ & $-35,810,002$ & $1,074.3$ & 215.4 & 36,733 & $1,836.6$ & -478.3 \\
\hline
\end{tabular}


For all scenarios defined in Table 1, Figure 6 shows the 2020 total welfare change (relative to the $20 \%$ RPS) resulting from any RPS target. As shown, using the non-LCA rates instead of the LCA rates (Scenario 2 relative to Scenario 1) has little effect on welfare change. This is reasonable given the fact that the use of LCA rates does not appreciably change GHG emission reductions for the comparative analysis. Under the higher $\mathrm{CO}_{2}$ social cost of $\$ 60$ /ton (Scenario 3), all RPS targets would produce welfare gains, with the 50\% RPS offering the highest welfare gain ( $\$ 595$ million). Increasing the $\mathrm{CO}_{2}$ social cost to $\$ 90 /$ ton (Scenario 4) would further favor higher RPS targets; the 50\% RPS would generate the most social gain for this case (with a total welfare gain of $\$ 1670$ million).

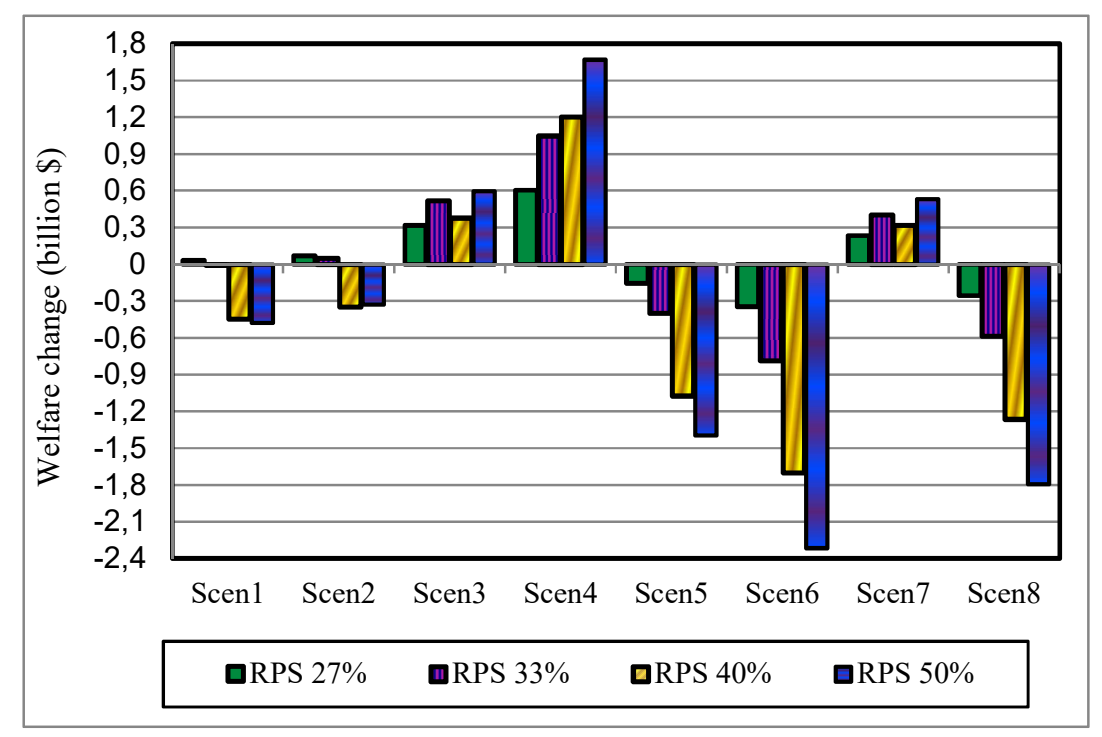

Fig. 6. Comparative 2020 welfare analysis for various RPS targets under different scenarios.

We can also observe in Figure 6 that using lower monetary value for employment (Scenario 5) drastically decreases the welfare gains from implementing an RPS target; even the 27\% RPS would decrease social welfare relative to the $20 \%$ RPS target. Without the inclusion of employment benefits (Scenario 6), even the 27\% RPS target would decrease social welfare by $\$ 344$ million. Note that many social benefit/cost studies do not directly include employment benefits in their analyses.

Scenario 7 addresses the effects of a drastic decrease in the renewable technology costs (assuming substantial technology improvements) in years after 2020, in place of the base assumption that the costs decrease smoothly over time. The less expensive future renewable generation would favor higher RPS targets, as expected; the 50\% RPS would bring about the highest welfare gains. 
Finally, Scenario 8 represents a lower carbon market price condition, assuming that the California Air Resources Board (CARB) floor prices would be adopted rather than the base carbon market forecasts. ${ }^{36}$ When using lower carbon market price forecasts, all RPS targets lead to higher total social welfare losses since with lower carbon reduction credits for renewables, RPS targets induce higher generation costs, relative to the $20 \%$ RPS. As can be observed in Figure 6, when assuming CARB floor prices (Scenario 8), the 27\% RPS would reduce total social welfare by $\$ 254$ million, compared to a social welfare gain of $\$ 33$ million by assuming our base carbon price scenario.

Summarizing the results, we can infer that under almost every scenario evaluated, the mandated $33 \%$ RPS does not offer the highest social welfare benefits. For relatively low carbon social cost values and smooth changes in technology costs, a slightly lower target, like the $27 \%$ RPS, would be more socially beneficial than the $33 \%$ RPS. This is primarily because generation costs would drastically increase at higher targets, and the higher GHG reduction and employment benefits cannot offset the higher generation costs. For high carbon social cost values, and/or when the cost of renewable generation declines substantially, higher RPS targets, like 50\%, would be more beneficial than the current mandated 33\% target, since higher RPS targets induce greater GHG emissions reductions. The choice of the $33 \%$ RPS mandate for California was not based on a detailed analysis of different RPS targets. Therefore, it is not clear how policy makers have chosen the mandated target over other targets. However, our analysis shows that California could be better off by implementing either a slightly lower target or a much higher target, depending on the social cost of GHG emissions, the employment benefit considerations, and the anticipated technology diffusion.

\section{Discussion and Conclusion}

Several interesting policy implications emerge from our study. Our analysis indicates that to meet any RPS target level for California, the average price of producing electricity will increase; however, our estimated price increase is lower than those found in other studies [8]. It is likely that previous studies have overestimated the costs of meeting RPS targets as a result of using constant demand forecasts. Another major finding is that California can meet all RPS targets using a variety of RPS eligible technologies. This result favors RPS policies for the state; if some renewable technologies may still need time for commercialization, the availability of other renewables that can fill the gap will reduce the potential risks of an RPS policy.

We estimated that the 33\% and 50\% RPS targets would mitigate GHG emissions by 17.6 and 35.8 million metric tons of carbon dioxide equivalent $\left(\mathrm{MMTCO}_{2} \mathrm{e}\right)$, relative to the $20 \%$ RPS. However, 
the average cost of reducing GHG emissions by an RPS would increase as the target increases, ranging from $\$ 71$ for the 33\% RPS to $\$ 94$ per ton of carbon dioxide equivalent emissions for the $50 \%$ RPS.

These values are relatively high compared to the prices prevalent in the current carbon markets [33-34], even though they are generally lower than the values found in other RPS studies [30]. As some studies have shown, California's RPS(s) may not be a cost effective option to reduce GHGs compared to other policies, e.g., a well-functioning and appropriately priced carbon market.

Using a detailed social benefit/cost analysis, we showed that the mandated 33\% RPS would not offer the highest social benefits under almost every scenario evaluated. For modest social cost of carbon and smooth reductions in technology costs, a slightly lower target (like the 27\% RPS) would provide the highest welfare gains among the studied RPS targets because, as RPS increases further, sudden jumps in generation costs would entirely offset GHG reduction and employment benefits. For high carbon social costs and/or when the cost of renewable generation substantially declines over time, higher RPS targets, such as $50 \%$, would be more beneficial to society than the current $33 \%$ target. Without employment benefits, all RPS targets would reduce total social welfare relative to the $20 \%$ RPS.

From a practical and policy perspective, this study focused on only one aspect of the RPS design: the RPS target value. Many other aspects of RPSs can be likewise studied and refined as necessary. The types of renewables to be eligible for the RPS, the duration and stability of targets, and the enforcement requirements are other aspects that should be analyzed in greater depth. Moreover, we did not study the consequences of the possibility that California may fail to meet its RPS targets [40]. Finally, while our model accounts for the effects of California's newly-established carbon market on the RPS policies, it does not account for the complex effects of RPS targets on the carbon market. Future work can address the above-mentioned limitations.

The analysis framework we have developed can be employed to evaluate RPS targets further in the future beyond 2020. Using our approach, policy makers can obtain important insights required for choosing among various RPS targets. As part of our future work, we will apply this study's approach to examine the social welfare effects of the 2030 RPS target for California, a subject of blistering political debates in the state. 


\section{Appendix A. Demand, Supply, and Equilibrium}

The original RPS Calculator is a Microsoft Excel spreadsheet partial equilibrium model which equilibrates the demand and supply of the electricity sector (Equation B1). In the original RPS Calculator, $D$ is the fixed total electricity demanded, and $S$ is the total electricity supplied as a function of supply cost, $P^{s}$ :

$$
D=S\left(P^{s}\left(\overline{\theta_{s}}, \overline{P_{f}}, R P S, \ldots\right)\right)
$$

Electricity demand in the RPS Calculator is currently static; the model applies the California Energy Commission (CEC) study's demand forecasts, but does not allow demand to change if electricity price changes [41]. That is, the CEC study have estimated demand by using electricity generation costs (prices) that are based on the $20 \%$ (or 30\%) RPS; as a result, the demand estimates are inconsistent with the demand expected over time from implementing other RPS targets. Our model incorporates short-run and long-run demand functions that are responsive to prices and estimates the demand endogenously. In addition, we updated the base demand forecasts of the RPS Calculator, using the 2013 integrated energy policy report (IEPR)'s electricity demand estimates [42].

The supply cost (price) is a function of: 1) $\overline{P_{f}}$, the vector of fuel (natural gas, coal, waste, etc.)

prices exogenously determined; 2 ) $\overline{\theta_{s}}$ the vector of parameters that affect the supply cost (other than fuel prices), e.g., capital and operating cost for all generation types; and 3) other parameters like the RPS target. Changes in any of the above parameters are likely to affect the supply function, and consequently the equilibrium electricity prices.

Aggregating the renewable cost and performance data, the RPS Calculator selects the renewable resources needed to meet the RPS target(s) and constructs the supply function in Equation B1. The RPS calculations start with an estimation of the renewable resources statewide that the California (regional) utilities must procure between 2008 and 2020 to meet a specified RPS target by 2020 . Then, the total energy resources required are calculated along with the required quantity of renewable energy, considering RPS percent of retail sales, minus the actual renewable generation claimed by California utilities in 2007. Finally, projects are ranked using a modified version of the renewable energy transmission initiative's (RETI's) “net value” approach [43] developed by the RETI Environmental Working Group.

The RPS Calculator estimates California's annual electricity generation costs in future years. In addition to the cost of constructing new energy resources, the RPS Calculator estimates changes in factors such as transmission, distribution, fuel costs, and $\mathrm{CO}_{2}$ allowance price, all of which result in a projection of California's total electricity expenditures in various horizon years under different scenarios 
(i.e., under different RPS targets). The resulting average electricity cost per $\mathrm{kWh}$ for each year is the total statewide electricity expenditure divided by total retail sales. However, California's retail rate designs vary among the electric utilities in the state, so the cost impact of meeting an RPS could be different for an individual household or business.

We use many of the same RPS Calculator data sources for the supply side calculations: (1) the California public utilities commission (CPUC) - Energy division project database [44]; (2) transmission data [43]; (3) fuel price and $\mathrm{CO}_{2}$ allowance price forecasts based on the Market Price Referent (MPR) methodology [45]; and (4) estimates of distributed renewable energy potentials using the E3 and Black and Veatch analysis [46]. All costs are expressed in 2008 dollars. The RPS Calculator does not attempt to predict breakthroughs in technological development or changes in capital or operational costs. Currently, the main driver of the conventional generation costs is the price of natural gas. The RPS Calculator assumes that all resources are developed by independent power producers (IPPs) using a 20year financing life. Based on the financing lifetime, the RPS calculates the resulting 20-year levelized $\$ / M W h$ power purchase agreement (PPA) price at the threshold that allows the IPP to achieve its target after-tax equity return.

We modified the RPS Calculator by adding two new features. First, realistically, electricity demand should respond to prices. Therefore, we replaced the fixed demand in Equation B1 to specify demand as a function of electricity prices:

$$
D\left(P^{d}\right)=S\left(P^{s}\left(\overline{\theta_{s}}, \overline{P_{f}}, R P S, \ldots\right)\right)
$$

where $P^{d}$ is the electricity price on the demand side (in $\$ / \mathrm{kWh}$ ). The assumed demand function is a simple Cobb-Douglas function with a constant elasticity, $e$ :

$$
D\left(P^{d}\right)=a \cdot\left(P^{d}\right)^{e}
$$

For the demand-price response, we assume a short-run elasticity of -0.1 and a long-run elasticity of -0.50 . Our elasticity assumptions are close to the average estimates found in other studies [47-49], especially in California-specific studies [50].

With this modification to the RPS Calculator, electricity demand responds to changes in the electricity sector that affect electricity prices. To that end, demand forecasts are updated using three main assumptions: (1) we assume that prices are equal to average costs or $P^{d}=P^{s}[50]$; (2) we calculate the total short-run demand in 2014 and the total long-run demand in 2020 based on the respective short-run and long-run demand functions given in Equation B3 with their respective elasticities, assuming that by 
2020, the long-run elasticity of -0.5 will be effective; and (3) we modify all the elements of total demand based on the updated total energy and their assumed shares of total demand in each year.

Each RPS Calculator run provides us with estimates of average annual costs of producing electricity (2008\$/KWH) for 2014 through 2020. The 2014 and 2020 electricity prices are determined with the assumption that prices $\left(P^{d}\right)$ equal average costs $\left(P^{s}\right)$. The prices are then used to estimate the 2015 and 2020 total demand. By updating demand values, the RPS calculator is run again. The new run results in new average costs, new prices, and new demand values. The procedure iteratively updates demand based on the updated costs (prices) of electricity $\left(P^{s}\right.$ or $\left.P^{d}\right)$ until demand and supply match [51].

\section{Appendix B. Fuel Price Distributions}

As the second extension, we allow some key RPS Calculator parameters and inputs related to electricity generation costs to be randomized. For example, because of uncertainty associated with future fuel prices, we allow fuel prices to be random variables with normal distributions. Figure B1 shows the probability density functions of 2020 fuel prices (in terms of 2008 dollars) adopted in this study. We determine the shown distributions based on the high, average, and low numbers from various studies [42 \& 52-53]. To use California-specific values, we borrow estimates mainly from the Klein study [52]. We use these values as our benchmark values and slightly modify them based on the RPS Calculator estimates. Since we need to use California-specific numbers, we use the AEO2012 Energy outlook values [53] only for the price of wood (the high and low wood prices have not been estimated for California). In addition, because of the rapid shale gas developments, we modify the natural gas prices using the 2013 IEPR's forecasts, which are based on the North American Market Gas Trade (NAMGas) model [42].

To estimate the distributions on Figure B1 from the high, medium, and average values, we assume that (1) the fuel prices are normally distributed, (2) the mean of the normal distribution is exactly at the determined medium (average) value, and (3) with a probability of 0.99 , the corresponding fuel cost would lie between the low and high estimates. Using these assumptions, we can determine the variance of the normal distribution and realize the normal distribution, using the estimated mean and the estimated variance.

By allowing these key parameters/inputs to vary randomly, the modified RPS model is able to capture the effects of different fuel price combinations (See Rouhani [54] for more details on the procedure). 


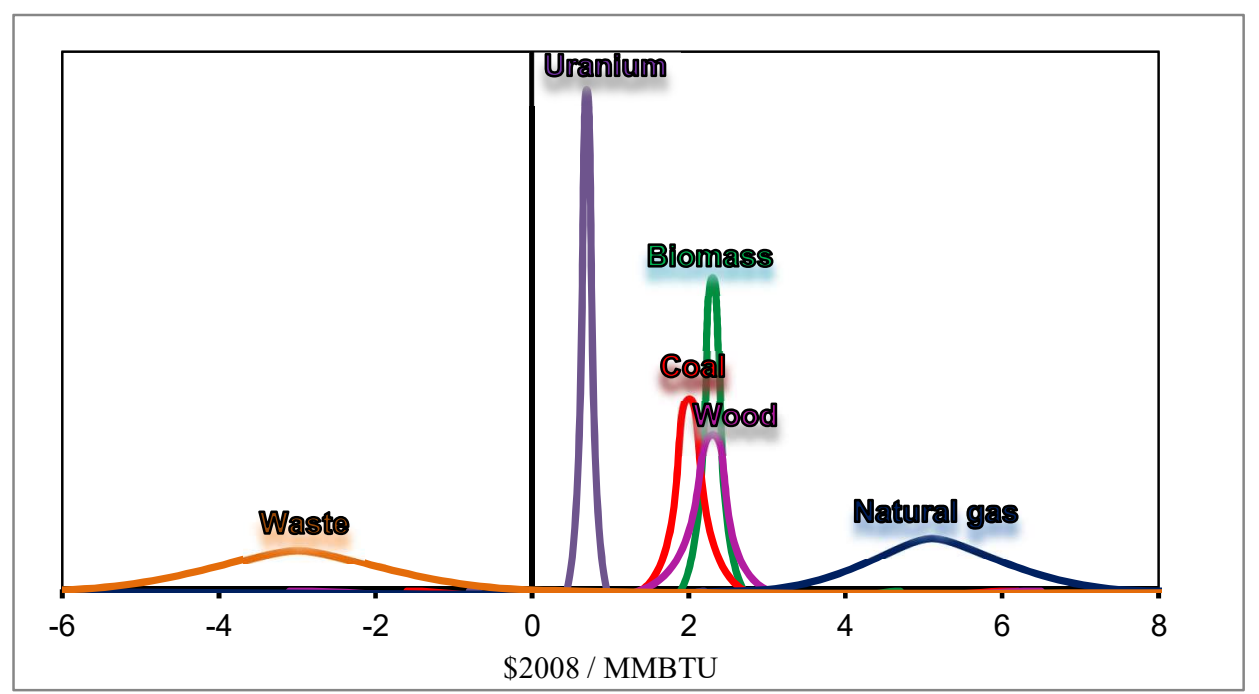

Fig. B1. Distributions of fuel prices in 2020

\section{Appendix C. GHGs, Criteria Pollutants, and Employment Calculations}

Three new modules are introduced to the RPS Calculator. These modules calculate the changes in GHG emissions, the criteria pollutant-related benefits of renewable generation, and labor under different RPS targets and different parameters assumed for electricity generation. Our GHG emissions calculations are based on two sets of emission rates (Table C1- row a): (1) the non-life-cycle analysis (non-LCA) values inherited from the RPS Calculator; and (2) the LCA values borrowed from the International Panel of Climate Change (IPCC) [55]. The default LCA values in the model are the median emission rate values determined by the IPCC study. Calculating the changes in both renewable and conventional generation (in GWh), we determine the changes in GHG emissions for different years by multiplying the change in each generation type by the corresponding emission rate for that generation type. Note that conventional generation is assumed to grow or shrink as needed, based on increases or decreases in natural gas generation only. 
Table C1 Model parameters for: (a) GHG emissions rates using LCA rates (1) and Non-LCA rates (2); (b) criteria pollutant benefits; (c) labor rates

\begin{tabular}{|c|c|c|c|c|c|c|c|c|c|c|c|}
\hline & Biomass & Biogas & $\begin{array}{l}\text { Geo } \\
\text { thermal }\end{array}$ & Hydro & $\begin{array}{l}\text { Solar } \\
\text { PV }\end{array}$ & $\begin{array}{l}\text { Solar } \\
\text { Thermal }\end{array}$ & Wind & $\begin{array}{l}\text { Natural } \\
\text { Gas }\end{array}$ & Nuclear & Coal & $\begin{array}{l}\text { Energy } \\
\text { Efficiency }\end{array}$ \\
\hline $\begin{array}{l}\mathrm{a}-1) \text { GHG Non-LCA } \\
(\mathrm{gr} / \mathrm{kWh})\end{array}$ & - & - & - & - & - & - & - & 181 & - & 500 & NA \\
\hline $\begin{array}{l}\text { a-1) GHG LCA } \\
(\mathrm{gr} / \mathrm{kWh})\end{array}$ & 37 & 55 & 45 & 4 & 46 & 22 & 12 & 469 & 16 & 1,001 & NA \\
\hline $\begin{array}{l}\text { b) Criteria pollut. } \\
\text { benefits }(\$ / M W h)\end{array}$ & 2.81 & 2.81 & 2.81 & 2.81 & 2.53 & 2.81 & 2.81 & - & - & - & NA \\
\hline c) Labor (job/GWh) & 1.31 & 1.31 & 0.72 & 0.77 & 1.14 & 0.41 & 0.1 & 0.04 & 0.31 & 0.27 & 0.32 \\
\hline
\end{tabular}

The second new module estimates the health-related benefits of reducing criteria pollutant emissions by various renewable electricity generation types, as compared with natural gas generation. The assumed monetary benefits per MWh are borrowed from the Siler-Evans' database (Californiaspecific data), which accounts for the public health and environmental damages of SO2, NOx, and primary PM2.5 emissions [56-57]. The damages are based on the Air Pollution Emission Experiments and Policy (APEEP) analysis model. The APEEP model values mortality from air pollution at $\$ 6$ million per life lost [58-59]. Note that the assumed marginal benefits for California are significantly lower than those of other states since renewable electricity generation in California mainly replaces cleaner natural gas generation (relative to coal) while in other states, it mainly replaces more dominant coal generation.

For the third module on labor calculation, we employed California's Clean Energy Future estimates of job creation rates [60] (the number of job-years per GWh) for different types of power generation, as shown in Table C1- row c, which includes the effects of subsidies and excludes the effects on other sectors. Using these rates, we calculate changes in labor from the base case to a specific scenario/case, as a result of any change in the generation mix. From this, we can calculate the change in labor based on two factors: (1) the change in each instate generation type multiplied by the corresponding rate in Table $\mathrm{C} 1$ - row c, and (2) the change in energy efficiency reductions multiplied by the corresponding job rate.

\section{Appendix D. Other Assumptions and Limitations}

We run the modified RPS model for a number of different major scenarios that reflect alternative RPS adoption levels. Specifically, we vary the RPS target levels between $20 \%$ and $50 \%$ and allow key 
parameters to vary randomly. For all other parameters in which we made no change, the RPS Calculator parameters are assumed at their default values.

In all scenario cases examined, the project selection (supply provision) is based on minimizing the costs of producing electricity, although other project selection criteria such as environmental considerations and commercial priorities could be assumed in the model as well. The social welfare loss projected from a decrease in demand is based on the rule of half [38-39].

Although our modeling represents a very significant step forward, we did have to make some simplifications, and there are some limitations that we would like to note. First and most important, our model does not take the details of conventional generation into account. A second simplification is that the uncertainties associated with future fuel costs and their distributions are applied exogenously. Endogenous uncertainties are generally more robust and realistic in formulating the potential relationships and correlations between fuel costs, i.e., these costs might move together or they might be affected by electricity prices.

One of our major assumptions about California's carbon market is that the carbon prices are exogenously determined, considering only two different carbon price trends: (1) modified future Green Exchange estimates as our base price forecasts, and (2) CARB Floor prices [61]. We then examine the impact of these two price trends on our analysis. In fact, our model does not account for the potential effects of RPS targets on carbon market prices.

Another limitation is that our analysis estimates the effects on the electricity sector as a whole. Extending the analysis into various sectors could be a useful addition. Moreover, the employment effects on sectors other than electricity should be considered in the social welfare analysis. Finally, we should include more detailed calculations of energy efficiency changes and electric vehicle demand in our modeling since the impact of these factors on the electricity sector are continuously growing.

\section{Appendix E. Impact of Shale Gas Development}

As we mentioned before, the price of natural gas is one of the main factors affecting conventional generation costs. The volatility in natural gas prices has important consequences for the California's electricity sector, which can also impact the social welfare calculations of various RPS targets.

Because of increased shale gas production in North America, natural gas prices have dropped dramatically [62]. Sudden declines in NG prices could make renewables and RPS policies less favorable since they expand the gap between the cost of renewable electricity generation and the cost of natural gas generation. The CPUC estimates of the effects of the 33\% RPS [63] and many other previous estimates [64] are based on natural gas price forecasts that did not account for the significant impact of 
shale gas development. The substantial decrease in natural gas prices, which is largely due to shale gas developments, is evident in the difference between the 2009 IEPR's forecasts and the 2013 IEPR's forecasts.

In this section, we examine the effects of the decrease in natural gas price forecasts on electricity prices. The average 2020 natural gas price forecast has declined from \$9/MMBTU (the 2009 IEPR forecast-without shale gas developments) to $\$ 4.5 / \mathrm{MMBTU}$ (the 2013 IEPR forecast-with shale gas developments). Table E1 summarizes the effects of this change in natural gas prices on electricity prices for the 2020 analysis year, under various RPS targets (all values are in 2008 dollars). Relative to the previous high natural gas price forecast scenario, electricity prices are estimated to decrease by $-5.85 \%$ to $-1.77 \%$; the effects are higher for lower RPS targets. Similarly, shale gas developments (natural gas prices) have substantial social welfare implications for electricity generation costs, emissions, and employment, all of which demonstrates the importance of taking into account complexities of a social welfare analysis since many unpredicted events can take place in the future.

Table E1 Impact of shale gas development on the RPS analysis- 2020

\begin{tabular}{lccc}
\hline & \multicolumn{3}{c}{ Electricity price } \\
\cline { 2 - 4 } & $\begin{array}{l}\text { Price } \\
\text { no shale gas } \\
(\$ / \mathrm{kWh})\end{array}$ & $\begin{array}{l}\text { Price } \\
\text { with shale gas } \\
(\$ / \mathrm{kWh})\end{array}$ & $\begin{array}{l}\text { percent } \\
\text { change }\end{array}$ \\
\hline RPS 20\% & 0.1619 & 0.1524 & $-5.85 \%$ \\
RPS 27\% & 0.1627 & 0.1576 & $-3.13 \%$ \\
RPS 33\% & 0.1677 & 0.1617 & $-3.57 \%$ \\
RPS 40\% & 0.1724 & 0.1698 & $-1.54 \%$ \\
RPS 50\% & 0.1775 & 0.1752 & $-1.30 \%$ \\
\hline
\end{tabular}




\section{References}

[1] Coffman, K, Griffin, J. P, Bernstein, P. An assessment of greenhouse gas emissions-weighted clean energy standards. Energy Policy 2012; 45 (1): 122-132.

[2] Holt, E, Wiser, R. The treatment of renewable energy certificates, emissions allowances, and green power programs in state renewables portfolio standards. Report prepared for Lawrence Berkeley National Laboratory, Berkeley, California, LBNL-62574, 2007; http://emp.lbl.gov/sites/all/files/REPORT\%20lbnl\%20-\%2062574.pdf.

[3] del Rio González, P. The interaction between emissions trading and renewable electricity support schemes: An overview of the literature. Mitig Adapt Strategies for Glob Change 2007; 12 (8): 1363-1390.

[4] Database of State Incentives for Renewables and Efficiency (DSIRE), 2014, Available online at: http://www.dsireusa.org/solar/solarpolicyguide/?id=21, Accessed August 30, 2014.

[5] Senate Bill SB2(X1), 2014. Available online at: http://www.leginfo.ca.gov/pub/11-12/bill/sen/sb 00010050/sbx1_2 bill 20110412 chaptered.pdf, Accessed December 2014.

[6] Kung, H. Impact of deployment of renewable portfolio standard on the electricity price in the state of Illinois and implications on policies. Energy Policy 2012: 44: 425-430.

[7] Chen, C, Wiser, R, Mills, A, Bolinger, M.Weighing the costs and benefits of state renewables portfolio standards in the United States: A comparative analysis of state-level policy impact projections. Renew Sustain Energy Revi 2009; 13.3: 552-566.

[8] California Public Utilities Commission (CPUC). 33\% RPS implementation analysis preliminary results. Report prepared for California Public Utilities Commission, 2009. Available online at: http://www.cpuc.ca.gov/NR/rdonlyres/1865C207-FEB5-43CF-99EBA212B78467F6/0/33PercentRPSImplementationAnalysisInterimReport.pdf, Accessed August 2012.

[9] Crane, K, Curtright, AE, Ortiz, DS, Samaras, C, Burger, N. The economic costs of reducing greenhouse gas emissions under a U.S. national renewable electricity mandate. Energy Policy 2011; 39 (5): 2730-2739.

[10] Barbosea, G, Birdb, L, Heeterb, J, Flores-Espinob, F, Wisera, R. . Costs and benefits of renewables portfolio standards in the United States. Renew Sustain Energy Revi 2015, 52, 523-533. 
[11] Kydes, AS. Impacts of a renewable portfolio generation standard on US energy markets. Energy Policy 2007; 35 (2): 809-814.

[12] Rouhani, OM, Kandel, A, Christian, M. The California renewable portfolio standard's impacts on the electricity sector in an uncertain cost environment. Internatl. J. Power Energy Syst 2013: 3 (3): 130-134.

[13] Keeler, AG State greenhouse gas reduction policies: a move in the right direction? Policy Sci 2007: 40: 353365.

[14] Delmas, MA, Montes-Sancho, MJ. U.S. state policies for renewable energy: context and effectiveness. Energy Policy 2011; 39 (5): 2273-2288.

[15] Huang, M, Alavalapati, JRR, Carter, DR, Langholtz, MH. Is the choice of renewable portfolio standards random? Energy Policy 2007; 35 (11): 5571-5575.

[16] Bedsworth, LW, Hanak, E. Climate policy at the local level: Insights from California. Glob Environ Change 2013; 23 (3): 664-677.

[17] Clemente, J. Is California's electricity policy really a model for the United States? Innov Energy Policies 1; 2011, Article ID E110302, 6 pages, doi:10.4303/iep/E110302.

[18] Palmer, K, Burtraw, D. Cost-effectiveness of renewable electricity policies. Energy Econ 2005; 27 (6): 873894.

[19] Johnson, E. The cost of carbon dioxide abatement from State renewable portfolio standards. Resour Energy Econ 2014; 36 (2): 332-350.

[20] Nogee, A, Deyette, J, Clemmer, S. The projected impacts of a national renewable portfolio standard. The Electr J 2007; 20 (4): 33-47.

[21] Mahone, A, Woo, CK, Williams, J, Horowitz, I. Renewable portfolio standards and cost-effective energyefficiency investment. Energy Policy 2009; 37 (3): 774-777.

[22] Bird, L, Chapman, C, Logan, J, Sumner, J, Short, W. Evaluating renewable portfolio standards and carbon cap scenarios in the U.S. electric sector. Energy Policy 2011; 39 (5): 2573-2585. 
[23] Mosey, G, Vimmerstedt, L. Renewable electricity benefits quantification methodology: A request for technical assistance from the California Public Utilities Commission. Technical Report NREL/TP-6A2-45639; July 2009.

[24] RPS Calculator-2012 version, 2012. Available online at: http://www.cpuc.ca.gov/PUC/energy/Procurement/LTPP/2012+LTPP+Tools+and+Spreadsheets.htm, Accessed August 2012.

[25] California Energy Commission (CEC). Integrated energy policy report (IEPR), Final Commission Report, December 2009, CEC -100-2009-003-CMF, 2009. Available online at: http://www.energy.ca.gov/2009publications/CEC-100-2009-003/CEC-100-2009-003-CMF.PDF, Accessed October 2012.

[26] Dahl, C. A survey of energy demand elasticities in support of the development of the NEMS. Washington, D.C. Contract No. DE-AP01-93EI23499, 1993.

[27] Bernstein, M, Griffin, J. Regional differences in the price-elasticity of demand for energy, National Renewable Energy Laboratory (NREL), 2006, Available online at: http://www.nrel.gov/docs/fy06osti/39512.pdf, Accessed August 2012.

[28] Kavalec, C, Fugate, N, Gorin, T, Alcorn, B, Ciminelli, M, Gautam, A, Sharp, G, Sullivan, K. California energy demand forecast 2012-2022 volume 1: Statewide electricity demand and methods. California energy commission, electricity supply analysis division, Publication Number: CEC - 200 - 2012 - 001 - SF - VI, 2012, Available online at: http://www.energy.ca.gov/2012publications/CEC-200-2012-001/CEC-200-2012-001-SFV1.pdf Accessed September 2012.

[29] Fetzer, T. Fracking growth. Working paper, London School of Economics, 2014.

[30] California Air Resources Board (CARB). Scoping plan attachment; 2008. Available online at: http://www.arb.ca.gov/cc/scopingplan/submittals/electricity/ucs_calwea_cec_arb_scoping_plan_submission_33_r ps1.pdf, Accessed January 2012.

[31] Del Rio, P. Analysing future trends of renewable electricity in the EU in a low-carbon context. Renew Sustain Energy Revi 15(5) (2011): 2520-2533. 
[32] Rouhani, OM. Clean Development Mechanism: An appropriate approach to reduce Greenhouse gas emissions from transportation? In 92nd Annual Meeting of the Transportation Research Board, Washington, D.C (No.13-3195), 2013.

[33] Kossoy, A, Guison, P. State and trends of the carbon market 2012. The World Bank, Washington, D.C., USA, 2012.

[34] California Air Resources Board (CARB). California Air Resources Board quarterly auction 1, 2012. Available online at:

http://www.arb.ca.gov/cc/capandtrade/auction/november_2012/auction1_results_2012q4nov.pdf, Accessed January 2013.

[35] Boardman, AE, Vining, AR. The political economy of public-private partnerships and analysis of their social value. Ann Public Cooperative Econ 2012; 83 (2): 117-141.

[36] Market Price Referent (MPR), 2011 model Available from:

http://www.cpuc.ca.gov/PUC/energy/Renewables/mpr

[37] Bureau of Labor Statistics. 2013 state occupational employment and wage estimates-California. Available online at: http://www.bls.gov/oes/current/oes ca.htm, Accessed December 2014.

[38] Rouhani, OM, Niemeier, D. Urban network privatization: A small network example. Transp Res Rec (TRR) 2011; 2221: 46-56.

[39] Rouhani, OM, Niemeier, D, Knittel, C, Madani, K. Integrated modeling framework for leasing urban roads: A case study of Fresno, California. Transp Res Part B. 2013; 48 (1): 17-30.

[40] Behles, D. Why California failed to meet its RPS target? Hastings West-Northwest J Environ Law Policy 2011; 17 (2): 163-196.

[41] California Energy Commission (CEC). Integrated energy policy report (IEPR), Final Commission Report, December 2009, CEC -100-2009-003-CMF, 2009. Available online at: http://www.energy.ca.gov/2009publications/CEC-100-2009-003/CEC-100-2009-003-CMF.PDF, Accessed October 2012. 
[42] California Energy Commission (CEC). Integrated energy policy report (IEPR), Final Commission Report, 2013, CEC-100-2013-001-CMF. Available online at: http://www.energy.ca.gov/2013publications/CEC-1002013-001/CEC-100-2013-001-CMF.pdf, Accessed December 2014.

[43] Renewable Energy Transmission Initiative (RETI) website, 2012. Available online at: http://www.energy.ca.gov/reti/documents/index.html, Accessed December 2012.

[44] ED Database- 2009 version website, 2009, Available online at: http://www.cpuc.ca.gov/NR/rdonlyres/F07E249B-C36A-4A38-8D36-

BDB88CDB154B/0/RPS_Project_Status_Table_1st_Quarter_2009.xls, Accessed August 2012.

[45] California Public Utilities Commission (CPUC). Market Price Referent (MPR) Methodology, 33 Percent RPS Implementation Analysis Interim Report; 2009. Available online at: http://www.cpuc.ca.gov/NR/rdonlyres/1865C207-FEB5-43CF-99EBA212B78467F6/0/33PercentRPSImplementationAnalysisInterimReport.pdf, Accessed March 2014.

[46] Energy and Environmental Economics (E3), Inc. Resource ranking and selection methodology for 33\% renewables portfolio standard implementation analysis, Fuel costs on Page 58, Table 17, 2009. Prepared for: California Public Utilities Commission, Available online at: http://www.cpuc.ca.gov/NR/rdonlyres/B3514A31D7B1-422C-ADA7-10F94E387914/0/ResourceRankingandSelection.pdf, Accessed August 2012.

[47] Dahl, CA. survey of energy demand elasticities in support of the development of the NEMS. Washington, D.C. Contract No. DE-AP01-93EI23499, 1993.

[48] Espey, JA, Espey, M. Turning on the lights: A meta- analysis of residential electricity demand elasticities. $J$ Agric Econ 2004; 36 (1): 65-81.

[49] Bernstein, M, Griffin, J. Regional differences in the price-elasticity of demand for energy, National Renewable Energy Laboratory (NREL), 2006, Available online at: http://www.nrel.gov/docs/fy06osti/39512.pdf, Accessed August 2012.

[50] Kavalec, C, Fugate, N, Gorin, T, Alcorn, B, Ciminelli, M, Gautam, A, Sharp, G, Sullivan, K. California energy demand forecast 2012-2022 volume 1: Statewide electricity demand and methods. California energy commission, electricity supply analysis division, Publication Number: CEC - 200 - 2012 - 001 - SF - VI, 2012, 
Available online at: http://www.energy.ca.gov/2012publications/CEC-200-2012-001/CEC-200-2012-001-SFV1.pdf Accessed September 2012.

[51] Rouhani, OM, Kandel, A. The Randomizer Program: Procedure and operating methods. Report prepared for California Energy Commission, MPRA Paper No. 53540, 2013. Available from: $\underline{\text { http://mpra.ub.uni- }}$ muenchen.de/53540/1/MPRA paper 53540.pdf, Accessed March 2014.

[52] Klein, J. Comparative costs of California central station electricity generation technologies, California Energy Commission, CEC-200-2009-017-SD, 2009. Available from:

http://www.energy.ca.gov/2009publications/CEC-200-2009-017/CEC-200-2009-017-SF.PDF, Accessed December 2014.

[53] Energy Information Administration's (EIA's). Annual energy outlook 2012 (AEO2012) with projections to 2035, 2012. Available from: http://www.eia.gov/forecasts/aeo/pdf/0383\%282012\%29.pdf, Accessed August $\underline{2012 .}$

[54] Rouhani, OM. Modified RPS Calculator: Inputs, updating procedure, and outputs. Report prepared for California Energy Commission, MPRA Paper No. 53679, 2013. Also available from: http://mpra.ub.unimuenchen.de/53679/1/MPRA_paper 53679.pdf, Accessed February 2014.

[55] Intergovernmental Panel on Climate Change (IPCC). Renewable Energy sources and climate change mitigation (SRREN). Special Report of the Intergovernmental Panel on Climate Change, Cambridge University Press, Cambridge, United Kingdom and New York, NY, USA, 1075 pp., 2011. Available online at: http://srren.ipcc-wg3.de/report, Accessed August 2012.

[56] Siler-Evans, K, Azevedo, IL, Morgan, MG, Apt, J. Regional variations in the health, environmental, and climate benefits of wind and solar generation. Proceedings of the Natl Acad Sci 2013, 110(29): 11768-11773.

[57] Marginal Emissions Factors Data Repository, Center for Climate and Energy Decision Making, Available online from: http://cedmcenter.org/tools-for-cedm/marginal-emissions-factors-repository/

[58] Muller, NZ, Mendelsohn, R, Nordhaus, W. Environmental accounting for pollution in the United States economy. The Am Econ Rev 2011; 101: 1649-1675. 
[59] Heo, J., Evaluation of Air Quality Impacts on Society: Methods and Application. PhD Thesis. Pittsburgh, PA: Carnegie Mellon University, 2015.

[60] California's Clean Energy Future. Preliminary estimates of job creation, 2012, Available online at: http://www.cacleanenergyfuture.org/documents/PreliminaryEstimatesofJobCreation.pdf, Accessed January 2013.

[61] Market Price Referent (MPR), 2011 model Available from:

http://www.cpuc.ca.gov/PUC/energy/Renewables/mpr

[62] Fetzer, T. Fracking growth. Working paper, London School of Economics., 2014.

[63] California Public Utilities Commission (CPUC). 33\% RPS implementation analysis preliminary results. Report prepared for California Public Utilities Commission, 2009. Available online at: http://www.cpuc.ca.gov/NR/rdonlyres/1865C207-FEB5-43CF-99EB-

A212B78467F6/0/33PercentRPSImplementationAnalysisInterimReport.pdf, Accessed August 2012.

[64] Rouhani, OM, Kandel, A, Christian, M. The California renewable portfolio standard's impacts on the electricity sector in an uncertain cost environment. Internatl J Power Energy Sys 2013; 3 (3): 130-134. 